\title{
AN ANALYTICAL FRAMEWORK FOR COLLABORATIVE CLOUD-BASED CAD PLATFORM AFFORDANCES
}

\author{
Marion, Tucker (1); \\ Olechowksi, Alison (2); \\ Guo, Junfeng (2) \\ 1: Northeastern University; \\ 2: University of Toronto
}

\begin{abstract}
Cloud computing has had an increasing influence on engineering and design. A hallmark of sites such as Github is the promise of rapid iteration and real-time collaboration. Recently, cloud collaborative software has migrated into the realm of physical product design, with computer-aided design (CAD) software platforms such as PTC's Onshape. In this research, we suppose that the effect of cloud collaborative software is multi-faceted; that this type of tool affords a number of new capabilities and behaviours for design individuals and teams. We develop a framework on how to contextualize the changes to design tasks afforded by the unique attributes of these cloud-based, collaborative design tools. We find evidence in our research of design engineers leveraging many aspects of the framework, particularly in learning and engagement with their team, and with resources available from communities of users. However, we find that real-world design engineers are not yet utilizing the full capability of synchronous cloud-platforms with respect to real-time synchronous design iteration within teams or communities.
\end{abstract}

Keywords: Computer Aided Design (CAD), Collaborative design, Design process

\author{
Contact: \\ Marion, Tucker \\ Northeastern University \\ Entrepreneurship and Innovation \\ United States of America \\ t.marion@neu.edu
}

Cite this article: Marion, T., Olechowksi, A., Guo, J. (2021) 'An Analytical Framework for Collaborative CloudBased CAD Platform Affordances', in Proceedings of the International Conference on Engineering Design (ICED21), Gothenburg, Sweden, 16-20 August 2021. DOI:10.1017/pds.2021.38 


\section{INTRODUCTION}

Cloud computing is a technology that has transformed data storage, information technology operations, and fostered the development of highly scalable digital platforms spanning nearly all aspects of our lives, from social media (e.g. Instagram and Facebook) to communications (e.g. Zoom and Microsoft Teams). Cloud computing, starting with software development, has had an increasing influence on engineering and design. In software development, platforms such as Github have enabled the development of large, collaborative communities. A hallmark of sites such as Github is the promise of rapid iteration and real-time collaboration. Recently, cloud collaborative software has migrated into the realm of physical product design, with computer-aided design (CAD) software platforms such as PTC's Onshape and Autodesk's Fusion 360. From a project-level, engineering task perspective, we still do not know the impact these new types of cloud-based collaborative design platforms will have on the activities of design.

In this exploratory research, we suppose that the effect of cloud collaborative software is multifaceted; that this type of tool affords a number of new capabilities and behaviours for design individuals and teams. We aim to unpack these effects, by generating an analytical framework for cloud collaborative platforms. To test this framework, we present a case study of cloud collaborative CAD software. We next demonstrate how this framework reveals insight aligning to the experiences of lead-users of this design software, as gleaned via interviews and study of online discussion boards. We conclude with thoughts on future research.

\section{LITERATURE REVIEW}

\subsection{Collaborative Platforms}

Design is a team undertaking, and therefore collaborative tools are critical for success. Ubiquitous internet and cloud computing and storage have enabled new models of work in many industries (Bailey et al., 2012), including new product design. Given the facilitation of communication and sharing they enable, collaborative IT tools have been shown to positively correlate with project performance (Marion et al., 2016). Yet "collaborative IT tools" contain a varied set of programs, such as cloud-based file sharing applications, blogs, Wikis, software development version control and, recently, collaborative computer-aided design.

In the context of learning, collaborative tools have emerged as a promising means to support pedagogical advances and new modes of teaching. Cloud computing tools for collaborative learning include synchronized tools (e.g. Google Docs), Learning Management System tools (e.g. Blackboard), and social networking tools (e.g. Twitter) (Al-Samarraie and Saeed, 2018). These tools were found to facilitate students' real-time interactions via learning activities, and promote a sense of ownership of their learning process. Synchronized tools were found to save time by reducing communication and coordination overhead. Therefore, the different characteristics of collaborative learning tools contribute differently to the outcomes derived from the tools.

Media theory puts forth a number of dimensions for analysing media technology broadly (Dennis et al., 2008), which may contribute to our understanding of collaborative platforms for design. For example, modern platforms enable Synchronicity, where actions move at the same rate, and exactly together. Another useful concept is Parallelism, the extent to which signals from multiple senders can be transmitted simultaneously. The concept of Symbol Sets represents the number of ways in which a medium allows information to be encoded for communication, which may be equivalent here to the variety of types of information shared through the collaborative platform. From a theoretical perspective, this research is centred on synchronicity, collaboration and cloud characteristics.

\subsection{Collaborative CAD}

CAD software is seeing its function set and application areas expand, emerging as a new collaborative platform. Horváth et al. (2015) discuss the "ubiquity" of CAD tools, defining the term: "Ubiquity refers to the trend that $\mathrm{CAD}$ moves out of the hands of specialists and becomes a ubiquitous asset of 
designing. [...] Ubiquity denotes the main promise of ubiquitous computing, namely, that it offers data collection and communication, modelling and representation, and computing and reasoning means and services anywhere, anytime, and in any context" (Horváth and Vroom, 2015). The authors argue that at the time, compared to the promise of ubiquitous computing, ubiquity of CAD had only seen limited impact, in particular because of a lack of feature integration into commercial systems. Given the advancement of a number of collaborative CAD technologies in the recent past, this conclusion deserves revisiting.

Research has begun to investigate the designer experience with commercially-available collaborative CAD packages. Some of these studies focused on differences between individual designers and design teams using synchronous CAD. Eves et al. (2018) conducted an experiment using Siemens NX 8, focusing on efficiency, emotion and communication. A related study focused on emotion by Zhou et al. (2021) using Onshape. These studies placed their emphasis on the behaviour and interaction of participants, while little attention was paid to the features of CAD tools. Researchers have come up with numerous methods to evaluate and compare CAD tools, but little attention was paid to synchronicity. Brisco et al. (2020) put forward an evaluation matrix for engineering design teams to evaluate the technology they use. In the paper, 19 requirements for Computer-Supported Collaborative Design (CSCD) were listed as a system to assess the CAD tools, while synchronicity was not included.

Although there are comparisons of CAD software, few previous systematic reviews from reliable sources for specific CAD tools have been performed. Germani et al. (2012) presented a QualityFunction-Deployment-based method to evaluate co-design platforms and their functions using evaluation matrices. Napoleone et al. (2020) discussed Cyber-Physical Systems (CPSs), which includes CAD tools. They reviewed and analysed the characteristics of CPSs, which encompasses collaboration and real-time capability. However, neither Germani's nor Napoleone's work considered specific CAD tools.

For those studies evaluating specific CAD tools, little research has focused on synchronicity, collaboration and cloud characteristics. Peng-jun et al. (2012) made a comparison, focusing on the file format and data exchanges between different CAD tools, while the comparison made by Pollák et al. (2017) cast light on process documentation. These comparisons did not involve the characteristics of cloud or collaboration.

$\mathrm{Wu}$ et al. (2016) reviewed some computer-aided tools for engineering design, computer-aided engineering, manufacturing and production. The authors put forth eight requirements for successfully cloud-based design and manufacturing systems, those relevant to design summarized as: social media integration, cloud-based distributed file system; open-source programming framework; multi-tenancy environment; provide Software-as-a-Service applications to users; support intelligent search engine to users to answer queries.

Two major gaps are seen in the current understanding of collaborative CAD tools: 1) a lack of differentiation amongst the features of the tools, and therefore lack of obscurity on the complex affordances of these new tools; 2) a lack of empirical studies of real designers and their experience with these new tools. In this research, we develop a framework on how to contextualize the changes to design tasks afforded by the unique attributes of these cloud-based, collaborative design tools.

\section{RESEARCH METHODOLOGY}

We chose to pursue a qualitative, inductive study as it is well-suited for this particular type of exploratory research in the field of technological innovation (Eisenhardt, 1989; Langley, 1999). We approached this research from a grounded theory perspective. Data collection and analysis involved a process of comparison and triangulation between historical research (literature and trade publications reviewed), observations and review of online discussion boards (community forums joined and observed for 6 months), and in-depth qualitative interviews (six interviews performed) to develop a sense of patterns within activities and tasks of the interview subjects (Miles \& Huberman, 1994; Glaser \& Strauss, 1967; Grodal, 2018). 
Using the recommendation of Yin (1994), we used in-depth case analysis to inform our research. The industry interviews were deliberately selected, and the methodology presented here is consistent with the objectives of qualitative research (Glaser and Strauss, 1965; Marion, Friar, and Simpson, 2012). We performed six in-depth, semi-structured interviews with practicing engineers that utilize a multitude of design and collaboration tools including PTC's Onshape. An interview guide was developed and used during the interview periods. Interviews were approximately 1 hour in length. We asked the interviewees to list and detail all the communication and design tools used during their projects, describe their use, and note the importance to their projects. The average working experience was 12 years, and each is a design or senior engineer who has responsibility of actively designing products using cloud CAD. All interviewees were male with a college degree. These interviews were performed over Zoom in the spring and summer of 2020. Two of the engineers were voluntary team leaders of a high school robotics program. An iterative, systematic analytic approach was used to analyse the data and code, in line with grounded-theory methods (Spradley, 1979). Following the recommendations of Glaser and Strauss (1965), from the coding process, key insights were synthesized from which the conceptual framework was developed.

\section{RESULTS AND DISCUSSION}

The changes afforded by cloud-based, synchronous platforms cut across a variety of dimensions. We propose that cloud-based design platforms have four main dimensions in which they impact knowledge creation, sharing and design. These dimensions include how designers and engineers collaborate during design, their approaches to design and engineering tasks, novel approaches to learning, and the involvement of user communities and applications to improve the platforms capability.

\subsection{Collaboration-Centric Design}

Cloud-based platforms such as Onshape allow real-time collaboration on design. Multiple engineers can work on the same part or assembly simultaneously. One can view this ability as the culmination of decades of progress on digitizing the NPD process. Over the last thirty years, almost every facet of the NPD process has become digital (Marion et al., 2012; Marion and Fixson, 2020). Over the last decade, the digitization of $\mathrm{R} \& \mathrm{D}$ activities has accelerated, and the impact on collaboration has gained increased attention (Orellana, 2017; Marion and Fixson, 2020). Recent research has shown that the use of IT tools tends to be associated with the intensity of collaboration (Peng, Heim, and Mallick, 2014), which in itself is correlated directly with knowledge development and sharing.

Workflows and interdependence of tasks during NPD, and their coordination has been shown to alter the relationship between collaborators (Claggett and Karahanna, 2018). Platforms like Onshape change the paradigm of collaboration, as the design tool allows for knowledge creation pathways that did not exist before. This can alter the intensity of tool use, which been shown in increase certain NPD outcomes such as the number of concepts generated (Marion et al., 2014). Platforms such as Onshape allow for synchronous or new synchronous design iteration.

During our research, we found some commonality of approaches to design and collaboration. One was the use of wikis such as Basecamp (www.basecamp.com) or Microsoft Teams to manage project tasks and general communication. One engineer noted: "We use Teams for file sharing and meetings. Teams chat is open all day, going back and forth. 'I'm having problems,' some might ask. I'll go over and follow him (in Onshape)." Our interviews showed that a modality of collaboration tools is used by teams, and they are often used concurrently. A team of students in the Robots to the Rescue competition used Google sheets, Slack, text messages, and Zoom to conduct design and related meetings. One team leader noted: "They do brainstorming and design virtually, I think it works for them on Zoom. They use breakout rooms. They share screens."

Given the global crisis due to COVID-19, many project teams had to switch to online virtual collaboration. From our limited sample of inquiry, we notice several themes. One is that platforms like Onshape are allowing real-time design collaboration, but importantly, these teams are using a multitude of collaboration tools often as the same time. While Onshape offers the ability to chat during 
design, our interviews noted that in each case, alternative communication platforms were used to support the collaborative CAD platform. We also noted that there are categories of use. One is joint editing of planning and project documents. For this, tools used include Google sheets, Microsoft Word in Sharepoint and Teams. "They use Google sheets to coordinate who is fixing what," noted one engineer. Text messages, Teams and Slack postings are used for instantaneous communication of design changes or updates. One team leader noted high usage, "30-40 messages per day on Slack". An engineer explained: "Concepts are discussed in Basecamp. Such as 'Make changes in the model.' The technical discussion happens in Onshape. Onshape would not be a good project management platform."

\subsection{Iterative Design Environment}

The unique attributes of collaborative design software appear to be changing design behaviour. One engineer noted: "We can all work on the same stuff together. We are usually not in the same parts studio together, we go in and out of each other's work. Especially now that we work remotely. He and I work from home." While they might not be working on the same part together, they are in the same design space. Messaging features within the Onshape also allow the transfer of design tasks from one individual to the next. An engineer noted: "The transition from me to a co-worker is a lot better. Hop into the document. I put in messages for my co-worker." This is allowing faster revision. As one engineer noted: "It's a new normal. It's faster, two guys can do more virtually." There is also a move to earlier sketching in CAD, changing the ideation phase. A team leader noted: "In the past, it was trying to build the hardware (a physical part). Now we use CAD-based ideation rather than building parts (physical). It's faster to move [digital] models rather than real life [physical models]." Another engineer stated: "Usually we go right in and start sketching. Parts studio helps with visualization. Be able to do it spatially with Master sketches." However, faster iteration and early conceptual design in CAD does not necessarily mean that engineers are becoming more aggressive or radical in their designs; our current research indicates that speed is improved, but the act of designing is similar. An engineer noted: "I wouldn't call it more aggressive design." Another noted: "I don't know if it changes my attitude."

However, in interviews, we noted some possible signals that aggressiveness and more radical iteration are possible. In the past, only one person would be designated the CAD lead. Now every person on the team has input. Everyone can participate in design ideation. A team leader noted: "The teams when trying to get idea across, they use Onshape. They develop 'throw away' Onshape models." Over time, just as waterfall coding gave way to Agile and SCRUM, massively collaborative CAD may yield a mechanical design culture much more similar to software design. This also allows a greater diversity of ideas, which can increase the novelty of design (Shah, Smith and Vargas-Hernandez, 2003). Our findings corroborate with recent research that shows that information technology intensity has a positive impact on innovation program performance and agility (Kroh, Luetjen, Globocnik, and Schultz, 2018; Marion and Fixson, 2020).

\subsection{Learning and Knowledge Creation}

Research has shown that knowledge flow is essential to innovation efforts (Marion et al., 2014; Nonaka and Takeuchi, 1995). The creation, iteration, and recombination of knowledge is paramount in innovation efforts (Henderson and Clark, 1990; Quintane, Mitch Casselman, Sebastian Reiche, and Nylund, 2011; Marion and Fixson, 2020). Collaborative platforms such as Onshape are fostering an environment that is centred on knowledge creation by enabling multiple users to create and share design information in real-time. We have observed several features of Onshape that further enhance this. One is the "follow" feature, which allows a user to shadow a designers input. This allows the designer to act as a teacher, stepping the follower through design changes as they happen. The value of this approach is confirmed in our interviews. One engineer noted: "We have a small team. Only three of them do CAD. We have been working from home (during the pandemic). I send a message, they hop on and follow and use the messaging tool in the document." A team leader noted: "In the in-room meeting, we project a screen with follow mode on to team. You work more and kids learn from modelling on screen. If someone has a question, switch to their model on 
screen. The productivity increase was noticeable. If you are sitting there working on the model you actually work." This also has ramifications for outside customers, vendors and manufacturers. As another engineer noted, he "could give a guy in the shop access to view the files as guest user, they could see the model (exploded view) so they could see how it gets put together, instead of them running to the front to see how the model looks - time efficiency right there." All together, these collaborative CAD tools like Onshape are increasing the power of the individual and team knowledge creation. This has been shown to improve innovation efforts (Lyytinen, Yoo, and Boland, 2016). This also can increase the transparency of iterations, further improving what has been a steady increase in CAD and IT tool performance and ability to communicate design changes (Marion and Fixson, 2020). An online discussion board post expressed: "This was our first year using Onshape [...] The switch has been transformational. We had 12 different students and 3 mentors contribute to the CAD this year. Last year we had 1 of each." While a limited study, our findings indicate that tools like Onshape can have a substantial impact on users new to CAD. Based on interviews, the ability to learn, follow, and 'jump in' to design can have a transformative impact on team performance. A team leader noted: "Now everyone is on CAD, from 1-2 modelers to 9-10 (out of 15). This increases the desire to explore designs. Students help one another. Once the team converts, it increasingly pays off."

\subsection{Community and Application Innovation}

One of the unique attributes of collaborative platforms is the community that arises to support it. For example, Github (as of 2020) has approximately 40 million users, 100 million repositories, and 32 million monthly visitors (DMR Business Statistics, 2020). These communities collaborate, share, mentor, answer questions, and solve problems. This is a hallmark of open innovation (Chesbrough, 2003), and is now being used for physical product design. Onshape's community takes cues from communities such as Github, fostered by the firm. An engineer noted: "Three years ago [the community] was limited. It has improved a lot. I have really liked the features that have been requested and added. They respond. A kind of community has developed. They listen. We requested a ton of stuff that's now in there. I sent in a ticket last month. They are pretty responsive. And they are transparent. They have been great to work with. It was a struggle early on." Another told us: "Yeah, more a sense of community. They pulled me in. I seem to be more engaged as a user. I was never in a forum for Solidworks, but here I am. I go look at it. Cool, I just got a notification. Style of engagement." Features within Onshape support community development, one important example being Featurescripts. Featurescripts are akin to a routine in Excel. For example, you may have a set design for a structural part with holes. The hole placement can be defined and made into a Featurescipt. This can then be shared with the community, and other uses can embed that feature in their designs. In reviewing discussion boards, we have seen substantial interaction related to these Featurescripts. This is similar to Github where routines or subroutines in programming code may be shared with the community. Additionally, Onshape features an applications store, similar in concept to the Apple App Store. Applications may include rendering tools, different analysis tools, and other plug-ins to enhance features of the overall platform. An engineer noted: "I used one plug-in for renderings of microfluidic cartridges." The development of the community and ability to build and share new applications and features open the platform to further development and engagement with users. As we have seen with software development, this can dramatically increase engagement, and ultimately the quality and quantity of design output.

\subsection{Challenges of synchronicity and cloud}

Both synchronous and cloud CAD software are novel design techniques and based on the above four dimensions, can offer the designer substantial advantages in their approach to design and ultimately outcomes. Nonetheless, although they may generate unprecedented positive working patterns for CAD tools to be synchronous or "cloud," the other side of the coin should be also considered.

The first challenge of cloud CAD tools is the concern about privacy. 3D models are the intellectual property of designers, sometimes even trade secrets. The cloud storage shifts the place of storage from the hard drive on premises, which designers know precisely where it is, to a server managed by the CAD developer or a third-party cloud service provider. The everywhere-access to the models empowers engineers to edit their models everywhere, but it also moves the model away from direct 
control by the organization. How to guarantee the safety of storage may be a crucial issue to the CAD tool suppliers.

Another potential challenge of fully cloud CAD tools is the lack of capability to work offline. Compared to on-premise CAD tools, fully cloud CAD tools have better performance with cheaper IT equipment investment. Nevertheless, there are scenarios when a designer would want to work without internet access, such as on a flight. Many partially cloud CAD tools provide offline mode to solve the problem, which outweighs fully cloud ones in this aspect.

A fully synchronous CAD tool makes it possible for two engineers to edit the same model concurrently, which is a new working pattern. However, this working pattern may cause conflicts and decrease efficiency in reverse. A designer may encounter an unexpected change made by his partner, which takes the designers extra time to communicate, and therefore cause loss of efficiency. Phadnis et al. (2021) conducted an experiment with Onshape, comparing the performance of designers working individually or in pairs. The result showed that single designers had better productivity than paired participants. The reason may be that single designers did not have to work around their partners' work. In this way, whether synchronous CAD facilitates design remains unknown, and more research is needed.

\section{IMPLICATIONS}

From our research, there are two overarching themes in how design is changing due to cloud design platforms such as Onshape. The first is the approach to design tasks itself, which we described above collaborative-centric (section 4.1) and iterative design environments (section 4.2). By their nature, cloud CAD platforms are designed to be more collaborative within distributed teams. However, what sets them apart is the ability to synchronously iterate. This is a real change from a more sequential approach to design and engineering. While real-time collaborative iteration has been applied to software for some time, and the related processes of agile development and SCRUM have been developed to support and give a process framework to this method of knowledge generation, for mechanical product design there is not yet a guiding process model to govern real-time iteration at a large scale. High product complexity and related complexity of the CAD assembly also complicates the potential for real-time iteration.

The second overarching theme is approaches to learning and engagement, as we noted in section 4.4. This includes not only engagement with other team members but engagement with outside communities. As we have seen with software, mechanical design is moving towards this model, with sites like GrabCAD showing how impactful these types of outside communities may be on design. Furthermore, now we have cloud-based design platforms that can support these types of engagements. We believe these two themes capture the larger trend of how physical design is migrating. In Figure 1, we show these two themes as axes. 


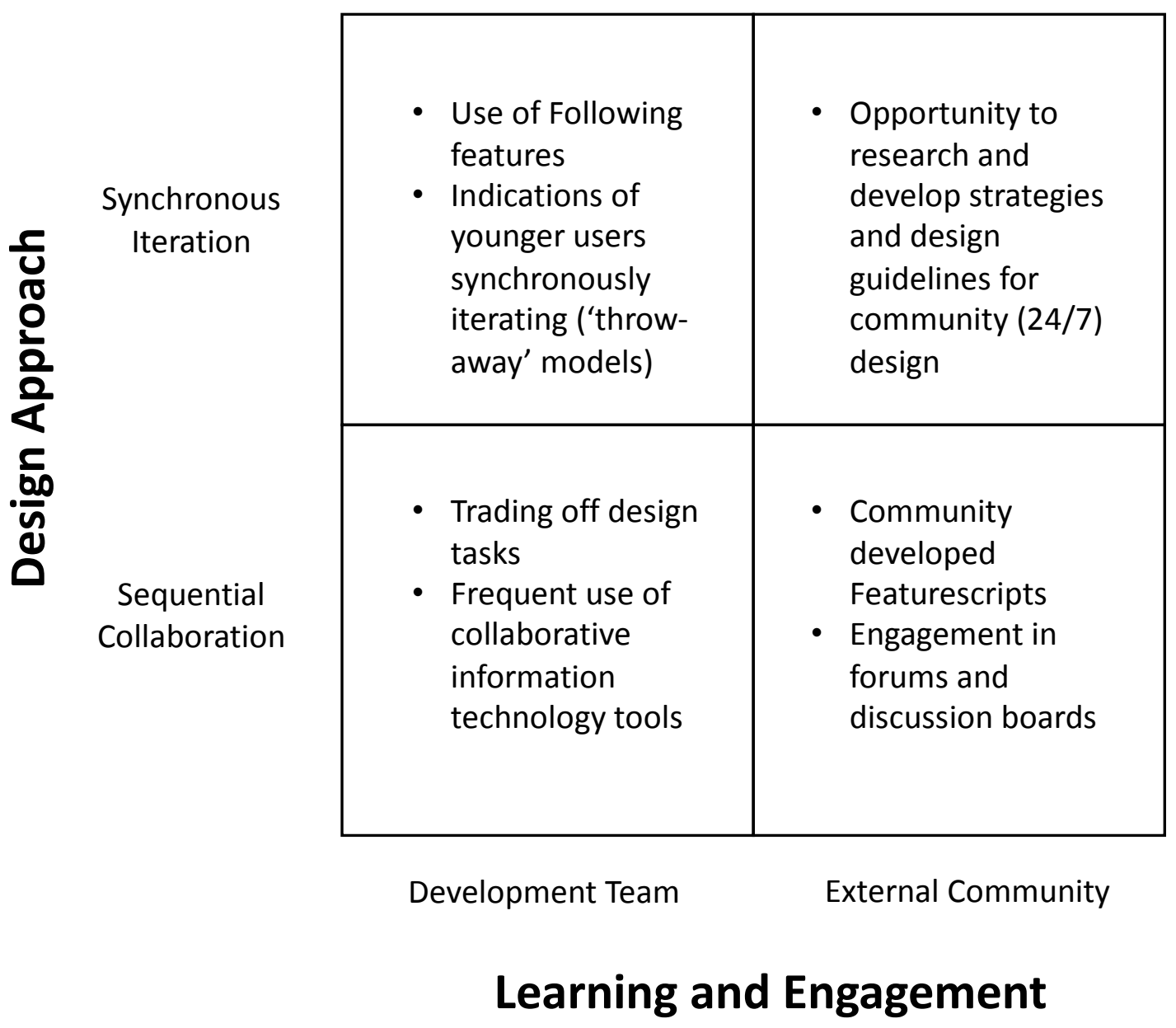

Figure 1. Cloud platform design framework

On the $\mathrm{x}$-axis is what we term Learning and Engagement. We illustrate two stakeholders, which can include the development team and the external community. Cloud CAD platforms can support both, with the follow feature and also their active community groups and forums. In our interviews, we see evidence of engineers leveraging both aspects to improve their design tasks. These can include instructing other team members on how a design problem was solved in the model, or downloading applications such as Featurescripts from Onshape forums. On the y-axis we note the design approach, noted here as sequential collaboration or synchronous iteration. In our research, all of the engineers we interviewed approached design, even though using Cloud CAD and the latest communication platforms, in a predominantly sequential collaborative design process. Although 21 st century tools are being used, the method for the act of design is still rooted in tradition. The areas less explored are synchronous iteration in real-time not only within the team, but within a community (upper right quadrant of the framework). While concerns managing design complexity, intellectual property, and general engineering management are valid, there remains a possibility that cloud-based design platforms catalyse a true shift in how design knowledge is created and developed. We have observed early indications of this shift with the school age designers we interviewed.

\section{CONCLUSIONS AND FUTURE RESEARCH}

In this research, we developed a framework with which to contextualize the potential of cloud-based design platforms like Onshape. We found evidence in our research of design engineers leveraging many aspects of the framework, particularly in learning and engagement with their team, and with resources available from communities of users. We also note that the engineers are engaging in highly collaborative design efforts, using a host of communication platforms and software to assist them. The platforms offer potential to radically change approaches to physical product design. However, our 
limited sample provides evidence that in real-world applications design is still approached in a sequential, asynchronous fashion, not yet utilizing the full capability of synchronous cloud-platforms. While this may be due to the newness of the platform, it also suggests that design guidelines, approaches to education and training, and engineering management methods are not sufficiently developed to maximize synchronous design. Going a step further, cloud-based platforms can allow synchronous iteration at a massive scale with community involvement. Future research needs to conceptualize and test how this approach might work, and fully understand challenges and opportunities therein.

\section{ACKNOWLEDGMENTS}

The authors would like to thank the interviewees for their time and insightful reflections.

\section{REFERENCES}

Al-Samarraie, H. and Saeed, N. (2018), "A systematic review of cloud computing tools for collaborative learning: Opportunities and challenges to the blended-learning environment", Computers and Education, Elsevier, Vol. 124 No. May, pp. 77-91.

Bailey, D.E., Leonardi, P.M. and Barley, S.R. (2012), “The Lure of the Virtual”, Organization Science, Vol. 23 No. 5, pp. 1485-1504.

Brisco, R., Whitfield, R.I. and Grierson, H. (2020), "A novel systematic method to evaluate computer-supported collaborative design technologies", Research in Engineering Design, Springer London, Vol. 31 No. 1, pp. 53-81.

Chesbrough, H. W. (2003). Open innovation: The new imperative for creating and profiting from technology. Harvard Business Press.

Claggett, J. L., \& Karahanna, E. (2018). Unpacking the Structure of Coordination Mechanisms and the Role of Relational Coordination in an Era of Digitally Mediated Work Processes. Academy of Management Review, 43(4): 704-722.

Dennis, A.R., Fuller, R.M. and Valacich, J.S. (2008), "Media, Tasks, and Communication Processes: A Theory of Media Synchronicity", MIS Quarterly, Vol. 32 No. 3, pp. 575-600.

DMR Business Statistics (2020). https://expandedramblings.com/index.php/github-statistics/. Accessed December 2, 2020.

Eisenhardt, K. M. 1989. Building theories from case study research. Academy of Management Review, 14(4): 532-550.

Eves, K., Salmon, J., Olsen, J. and Fagergren, F. (2018), “A comparative analysis of computer-aided design team performance with collaboration software", Computer-Aided Design and Applications, Vol. 4360, pp. 1-12.

Germani, M., Mengoni, M. and Peruzzini, M. (2012), "A QFD-based method to support SMEs in benchmarking co-design tools", Computers in Industry, Elsevier B.V., Vol. 63 No. 1, pp. 12-29.

Glaser, B.G., Strauss, A.L., 1967. The discovery of grounded theory: Strategies for qualitative research. Aldine Publishing Company, Chicago.

Grodal, S. 2018. Field expansion and contraction: How communities shape social and symbolic boundaries. Administrative Science Quarterly, 63(4): 783-818.

Henderson, R. M., \& Clark, K. B. (1990). Architectural innovation: The reconfiguration of existing. Administrative science quarterly, 35(1), 9-30.

Horváth, I. and Vroom, R.W. (2015), "Ubiquitous computer aided design: A broken promise or a Sleeping Beauty?”, CAD Computer Aided Design, Elsevier Ltd, Vol. 59, pp. 161-175.

Kroh, J., Luetjen, H., Globocnik, D., \& Schultz, C. (2018). Use and Efficacy of Information Technology in Innovation Processes: The Specific Role of Servitization. Journal of Product Innovation Management, 35(5), 720-741.

Langley, A. (1999). Strategies for theorizing from process data. Academy of Management review, 24(4), 691710.

Lyytinen, K., Yoo, Y., \& Boland Jr, R. J. (2016). Digital product innovation within four classes of innovation networks. Information Systems Journal, 26(1), 47-75.

Marion, T. J., \& Fixson, S. K. (2020). The Transformation of the Innovation Process: How Digital Tools are Changing Work, Collaboration, and Organizations in New Product Development. Journal of Product Innovation Management.

Marion, T.J., Reid, M., Hultink, E.J. and Barczak, G. (2016), "The influence of collaborative IT tools on NPD", Research Technology Management, 2016, Vol. 59 No. 2, pp. 47-54.

Marion, T. J., Barczak, G., \& Hultink, E. J. (2014). Do social media tools impact the development phase? An exploratory study. Journal of Product Innovation Management, 31, 18-29. 
Marion, T. J., Friar, J. H., \& Simpson, T. W. (2012). New product development practices and early-stage firms: Two in-depth case studies. Journal of Product Innovation Management, 29(4), 639-654.

Marion, T., Fixson, S., \& Meyer, M. H. (2012). The problem with digital design. MIT Sloan Management Review, 53(4), 63-68.

Miles, M. B., \& Huberman, A. M. 1994. Qualitative data analysis: An expanded sourcebook. Sage.

Napoleone, A., Macchi, M. and Pozzetti, A. (2020), “A review on the characteristics of cyber-physical systems for the future smart factories", Journal of Manufacturing Systems, Elsevier, Vol. 54 No. August 2019, pp. 305-335.

Nonaka, I., \& Takeuchi, H. (1995). The knowledge-creating company: How Japanese companies create the dynamics of innovation. Oxford university press.

Orellana, S. (2017). Digitalizing Collaboration. Research-Technology Management, 60(5): 12-14.

Peng, D. X., Heim, G. R., \& Mallick, D. N. (2014). Collaborative Product Development: The Effect of Project Complexity on the Use of Information Technology Tools and New Product Development Practices. Production and Operations Management, 23(8): 1421-1438.

Peng-jun, M., Fu, Z. and Zhang, G.Y. (2012), "Data exchange method between ADAMS, CATIA and SolidWorks software", Applied Mechanics and Materials, Vol. 143-144, pp. 422-427.

Phadnis, V.S., Wallace, D.R. and Olechowski, A. (2021), “A multimodal experimental approach to study CAD collaboration”, Computer-Aided Design and Applications, Vol. 18 No. 2, pp. 328-342.

Pollák, M., Baron, P. and Kočiško, M. (2017), "Comparison of process documentation generation in PTC Creo and NX systems", MATEC Web of Conferences, Vol. 137, https://dx.doi.org/10.1051/matecconf/201713706004.

Quintane, E., Mitch Casselman, R., Sebastian Reiche, B., \& Nylund, P. A. (2011). Innovation as a knowledgebased outcome. Journal of knowledge management, 15(6), 928-947.

Shah, J. J., Smith, S. M., \& Vargas-Hernandez, N. (2003). Metrics for measuring ideation effectiveness. Design studies, 24(2), 111-134.

Spradley, J. 1979. Asking descriptive questions. The Ethnographic Interview, 1: 44-61.

Wu, D., Terpenny, J. and Schaefer, D. (2016), “A Survey of Cloud-Based Design and Engineering Analysis Software Tools", Proceedings of the ASME 2016 International Design Engineering Technical Conferences \& Computers and Information in Engineering Conference IDETC/CIE 2016, pp. 1-9.

Yin, R.K., 1994. Case study research - design and methods, 2nd ed. Sage Publications, Thousand Oaks, CA

Zhou, J., Phadnis, V. and Olechowski, A. (2021), "Analysis of Designer Emotions in Collaborative and Traditional Computer-Aided Design”, Journal of Mechanical Design, Vol. 143 No. February, pp. 021401 1-10. 